\title{
O AUMENTO DO CONSUMO DE ÁLCOOL E DE BENZODIAZEPÍNICO: ALPRAZOLAM NO PERÍODO DA PANDEMIA DO COVID-r9
}

\author{
Letícia Ferreira Brito ${ }^{1}$
}

Thiago Pereira de Abreu ${ }^{2}$

RESUMO: $O$ artigo apresenta um levantamento feito sobre os efeitos que o isolamento social da pandemia do COVID-19 trouxe com o decorrer do tempo. Os dados coletados foram com base em artigos científicos e em pesquisa de campo em uma drogaria onde a venda do benzodiazepínico Alprazolam teve um alto crescimento em sua venda comparado ao ano anterior a pandemia. $\mathrm{O}$ isolamento social foi o ponto de partida para que transtornos do humor tomasse conta de muitas pessoas, já que suas rotinas foram mudadas radicalmente de uma forma repentina. Com diversas mudanças o sentimento de medo, angustia, tristeza tomaram conta da grande população levando a um desequilíbrio no humor, como ansiedade, depressão e crise do pânico, levando um aumento no consumo de álcool e ocasionando uma maior procura e uso de ansiolíticos para um melhor bem estar.

Palavras-Chave: Pandemia. Benzodiazepínicos. Alprazolam. Depressão. Ansiedade.

ABSTRACT: The article presents a survey of the effects that the social isolation of the COVID-I9 pandemic brought over time. The data collected was based on scientific articles and field research at a drugstore where the sale of the benzodiazepine Alprazolam had a high growth in its sales compared to the year before the pandemic. Social isolation was the starting point for mood disorders to take over many people, as their routines were radically changed in a sudden way. With several changes, the feeling of fear, anguish and sadness took over the large population, leading to an imbalance in mood, such as anxiety, depression and panic attacks, leading to an increase in alcohol consumption and causing a greater demand and use of anxiolytics for a better well being.

\footnotetext{
Aluna do curso Bacharel em Farmácia da Universidade.. Iguaçu. Email:leticia.b.ferreira@hotmail.com.

2 Doutor em Fisiologia pela UFRJ. E-mail: thiagoabreuo7o4@hotmail.com
} 
Keywords: Pandemic. Benzodiazepines. Alprazolam. Depression. Anxiety.

\section{INTRODUÇÃO}

Com a pandemia do COVID-ı9 o isolamento social foi a maneira mais eficaz para controlar a proliferação do vírus. A população precisou passar por mudanças em sua rotina como ficar em casa por muito tempo, e algumas tiveram a alteração do serviço presencial para home office, mas com quase dois anos de pandemia transtornos do humor como ansiedade, depressão e crise do pânico começaram a atingir grande parte da população, que sofreu impactos em suas vidas como o desemprego, fechamento de empresas, perda de familiares entre outros. (BEZERRA, Anselmo; SILVA, Carlos; SOARES, Fernando; SILVA, José,2020)

Com o lockdown, a população não tinha mais os bares e restaurantes para poder ter seu tempo de lazer, se reunir com amigos e familiares. E o que era consumido nesses locais, com o serviço de delivery passou a ter a opção de estar sendo consumido dentro de casa. Logo, quem tinha o hábito de sair para beber aos finais de semana por estar de folga do trabalho, passou a beber frequentemente, aumentando assim o seu consumo, já que com o isolamento, não poderia ir para lugar algum. (GIGLIOTTI, 202I)

Diante dessas mudanças na rotina da população, sentimentos como angustia por não poder sair de casa, nem mesmo para trabalhar, tomou conta de todos. Os transtornos do humor se potencializaram causando depressão e crise do pânico, e o consumo de alcool está diretamente ligado a esses distúrbios já que o álcool possui um efeito sedativo e relaxante. (BEZERRA, Anselmo; SILVA, Carlos; SOARES, Fernando; SILVA, José, 2020)

O que a grande maioria espera é que o álcool o faça esquecer dos problemas e de situações difíceis e isso é um equívoco, já que com a falta de moderação em seu uso, o seu efeito pode potencializar e agravar quadros de ansiedade, estresse, depressão e crise do pânico. (GIGLIOTTI,202ı) 
Uma outra substância também teve um grande aumento durante a pandemia, os Benzodiazepínicos (BZDs), seu consumo cresceu em números preocupantes, trazendo uma grande alerta já que ele e o álcool possuem efeito dependente e abstinência. (CFF,2020)

Os benzodiazepínicos surgiram acidentalmente no meado da década de 1950. Atualmente são conhecidos como "tarja preta" os ansíoliticos tratam da ansiedade, possuindo efeito sedativo, hipnótico, anticonvulsivante e relaxante muscular. Essa classe de medicamento é a mais prescrita e consumida em todo mundo, inclusive no Brasil. (LEONARDI; AZEVEDO; OLIVEIRA; 2017)

Seu mecanismo de ação acontece através do estímulo na inibição do receptor GABA, facilitando a abertura dos canais de cloreto. Com o acumulo de carga negativa no interior da célula, é causado uma hiperpolarização da membrana neural, diminuindo a passagem da corrente elétrica. Seu tempo de ação pode variar entre longa, intermediária e curta ação (MOREIRA, Pamela; BORJA, Amélia).

Seu efeito promove a liberação de hormônios como a noradrenalina, serotonina e outros, para a estabilização de humor. Em consequência dessa ação ele produz uma depressão na atividade cerebral, diminuindo assim a ansiedade, trazendo um maior bem estar e conforto, possuindo um efeito ansiolítico para quem sofre com esses problemas (LEONARDI; AZEVEDO; OLIVEIRA; 2017).

Em uma pesquisa o Alprazolam (Frontal) que tem o nome químico 8-cloro-Imetil- 6-fenil- ${ }_{4} \mathrm{H}$-s-triazolo-(4,3-alfa) $(\mathrm{I}, 4)$ benzodiazepina, triazolo análogo da classe de I,4-benzodiazepínicos. Apresentou um aumento comparado ao ano anterior a pandemia, justamente por ser um ansiolítico e também ser eficaz no tratamento de abstinência alcoólica (PFIZER, 2020).

Seu mecanismo de ação exato é desconhecido. Como é um fármaco da classe dos BZDs, seu mecanismo se enquadra a classe. Sua administração é por via oral, apresentando uma fácil absorção. Sua concentração plasmática acontece em cerca ih a $2 \mathrm{~h}$ após sua administração, os picos de concentração são proporcionais a dosagem 
administrada. O fármaco possui uma meia-vida média variando de (6,3 a 26,9h). Sua dosagem varia de $0,25 \mathrm{mg}$ a $2 \mathrm{mg}$ (PFIZER, 2020).

O Alprazolam assim como outros fármacos, é excretado pela urina. Sua contraindicação é em pacientes que apresentam hipersensibilidade a benzodiazepínicos ou a qualquer componente do alprazolam, a pacientes portadores de miastenia gravis, pacientes com glaucoma com ângulo estreito agudo também é contraindicado, já pacientes com glaucoma com ângulo aberto pode ser usado. Para grávidas e lactantes esse medicamento não é indicado (PFIZER, 2020).

Suas reaçãos adversas quando apresentavéis ocorrem no ínicio do tratamento, causando sonolência, cefaleia, sedação, disartria, comprometimento da memória, ataxia, tontura, fadiga, constipação, irritabilidade, boca seca, durante o tratamento os efeitos podem desaparecer (PFIZER, 2020).

\section{OBJETIJOS}

2.1 Objetivo geral

Evidenciar os efeitos causados pela pandemia, diante de pessoas que sofreram transtornos do humor pelas mudanças e perdas em suas vidas, levando as mesmas ao consumo elevado do álcool e desencadeando de certa forma uma necessidade de tratamento farmacológico de benzodiazepínicos, principalmente o Alprazolam.

\subsection{Objetivos específicos}

- Abordar o aumento do uso de benzodiazepínicos na pandemia, para o tratamento de ansiedade e depressão.

- Discorrer sobre o aumento do consumo de alcool na pandemia, e a incentivação do consumo em lives.

\section{METODOLOGIA}

Esta pesquisa tem caráter qualitativo, descritivo, com fontes primárias baseando-se em artigos científicos, revistas, sites e bula. Com intuito de alertar os riscos do aumento do uso de benzodiazepínicos na pandemia, especificamente o Alprazolam no período de janeiro a dezembro de 2020 em comparação com as vendas 
no mesmo período do ano anterior, 2019. Os dados foram coletados na farmácia Nova Drogaria.

\section{JUSTIFICATIVA}

O benzodiazepínico Alprazolam teve um aumento em seu consumo, no período da pandemia onde a população ficou em isolamento social, provocando transtornos do humor em grande parte da sociedade. Levando a ansiedade, depressão e crise do pânico. Trazendo um alerta já que se trata de um medicamento de controle especial, e que pode causar dependência e tolerância farmacológica.

\section{DESENVOLVIMENTO}

Problemas silenciosos da pandemia do COVID-19. Além de levar milhares de pessoas a óbito a pandemia tem trazido problemas que a mídia não transmite e nem mesmo os canais de comunicação como Facebook, Instagram, Twitter entres outros. Com o isolamento social artistas viram uma grande oportunidade de investir em LIVES (Transmissão ao vivo de áudio e vídeo na Internet). Mas com as LIVES propagandas eram feitas, principalmente de bebidas alcoólicas, levando o público ao um consumo maior das mesmas (AÇÃO, 2020).

Com o isolamento social trazendo grandes preocupações, perdas, medos e inseguranças logo transtornos do humor são gerados, e com a associação da bebida alcoólica é provocado uma potencialização nos sintomas que cada transtorno causa (GIGLIOTTI, 202I).

Pesquisas apontam que com o isolamento social o consumo de álcool e benzodiazepínicos aumentaram em níveis alarmantes, uma vez que não se sabe até quando estaremos em uma pandemia. A venda de bebidas alcoólicas subiu 93,9\%, com 248,9 mil compras realizadas. (NEVES, 2021) Enquanto o número de vendas de benzodiazepínicos teve um aumento de 13,84\% em comparação ao ano de 2019 (CFF, 2020).

Em uma pesquisa feita no estado do Rio de Janeiro, especificamente no município de Nova Iguaçu, na farmácia Nova Drogaria, foi detectado um aumento 
do benzodiazepínico Alprazolam durante o ano de 2020 em comparação a 2019. Justamente o período de pandemia. O gráfico a seguir detalha a quantidade e a miligrama do fármaco em questão.

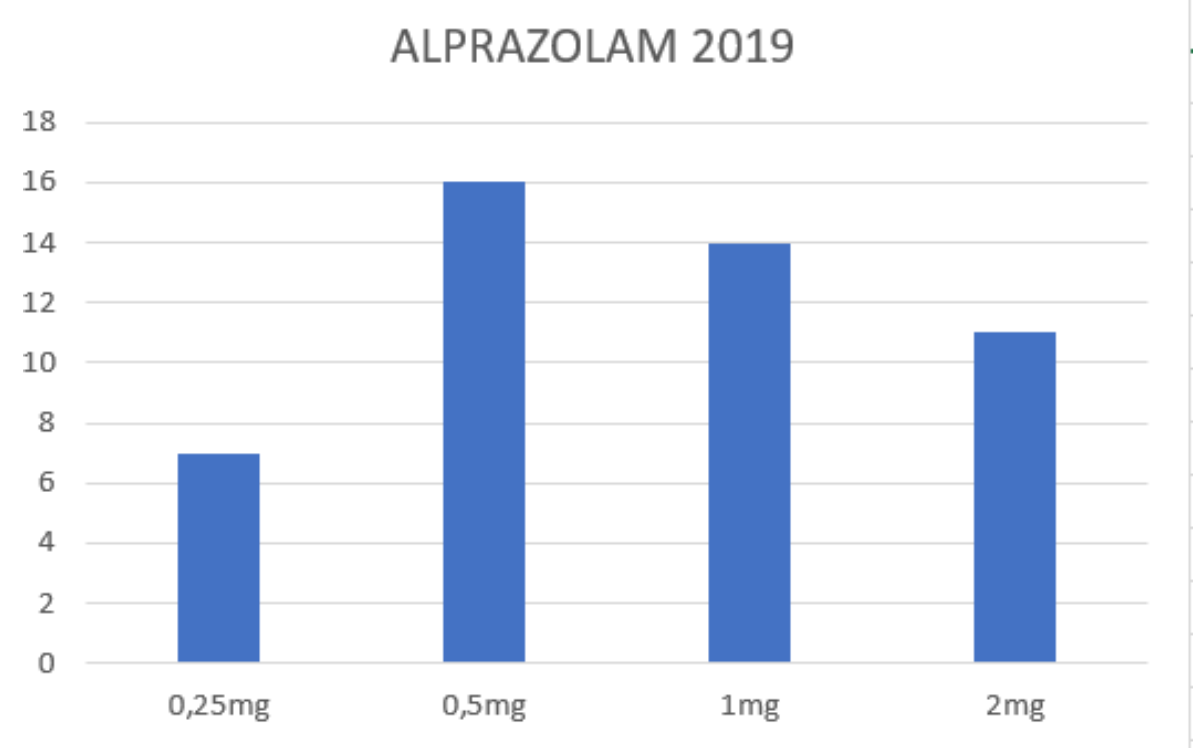

(Nova Drogaria, 2019)

Quantidade de vendas referente a cada miligrama no ano de 2019



Quantidade de vendas referente a cada miligrama no ano de 2020 
O uso do álcool associado com o benzodiazepinico traz um grande perigo já que com essa interação o álcool promove um aumento na depressão do sistema nervoso central e a na absorção do fármaco, potencializando o efeito que o mesmo promove. A intoxicação por essas substâncias pode causar insuficiência respirátoria, dificuldade na fala, perda de consciência, fraqueza muscular, coma e podendo levar a morte.

\section{DISCUSSÃO}

Com base na pesquisa feita e com os resultados encontrados, de fato o Alprazolam tem um aumento em seu consumo, no período de pandemia. Trazendo um grande alerta já que de acordo com a Organização Mundial da Saúde (OMS, 2013) é que os benzodiazepínicos não devem ser oferecidos a adultos para reduzir os sintomas de estresse traumático agudo associados a um prejuízo significativo no funcionamento diário no primeiro mês após um evento potencialmente traumático. As principais preocupações sobre o uso de benzodiazepínicos são que muitas pessoas desenvolvem tolerância aos seus efeitos, obtêm poucos benefícios terapêuticos com o consumo crônico, tornam-se dependentes deles e sofrem uma síndrome de abstinência quando param de tomá-los. Não há evidências sobre os benefícios dos benzodiazepínicos, um ansiolítico comum, sobre os sintomas de estresse traumático após um evento potencialmente traumático recente. Os benzodiazepínicos podem diminuir o tempo de recuperação de eventos potencialmente traumáticos.

\section{CONCLUSÃO}

Com esta pesquisa nota-se um grande aumento no uso do benzodiazepínico Alprazolam e de álcool, no período da pandemia do covid-ı́, levando a uma reflexão sobre os impactos que a pandemia tem nos causado. O tratamento com Alprazolam na maioria dos casos de transtornos do humor é eficaz, porém com tempo indeterminado para o fim da pandemia, causa questionamentos e preocupações, sobre até quando esses impactos afetaram a população. Podendo assim causar dependência 
farmacologica, tolerância e a longo prazos outros tipos de problemas. Já o uso de álcool nos traz muitas preocupações com o seu consumo excessivo, podendo levar ao vicío e doenças graves podendo ocasionar a morte.

\section{REFERÊNCIA}

AÇÃO,Vida Abuso de álcool em lives: mistura perigosa em tempos de pandemia. Disponível em: 〈https://www.vidaeacao.com.br/lives-e-abuso-de- alcool-misturaperigosa-em-tempos-de-pandemia/ >. Acesso 29 setembro 202I

BEZERRA, Anselmo; SILVA, Carlos; SOARES, Fernando; SILVA, José)Fatores associados ao comportamento da população durante o isolamento social na pandemia de COVID-19. 2020

CFF, 2020) Venda de medicamentos psiquiátricos cresce na pandemia. CONSELHO FEDERAL DE FARMÁCIA. Disponível em:<http://covidig.cff.org.br/venda-demedicamentos-psiquiatricos-cresce-na-pandemia/ >. Acesso em o9 setembro 202I

GENEBRA Who releases guidance on mental health care after trauma. OMS. Diponível em: <https://www.who.int/news/item/o6-o8-2013-who-releases guidance-on-mental-health-care-after-trauma>. Acesso or outubro 202I

GIGLIOTTI, Analice A pandemia de bebida alcoólica. VEJA RIO. Disponível em: $<$ https://vejario.abril.com.br/blog/manual-de-sobrevivencia-no-seculo-

21/pandemia-bebida-alcoolica/>. Acesso em 29 setembro 202I

LEONARDI,Jéssica; AZEVEDO,Bruna; OLIVEIRA, Ana. Benzodiazepínicos e Seus Efeitos no Sistema Nervosocentral. REVISTA SAÚDE EM FOCO - Edição no 9 - Ano: 2017

MOREIRA, Pamela; BORJA, Amélia. Benzodiazepínicos: Uso e Abuso em Pacientes Idoso. CENTRO DE PÓS-GRADUAÇÃO, PESQUISA E EXTENSÃO OSWALDO CRUZ. 2019.

NEVES, Úrsula. Consumo de bebidas alcoólicas cresce $93,9 \%$ na quarentena. PEBMED. Disponível em: < https://pebmed.com.br/consumo-de-bebidasalcoolicas-cresce-939-na-quarentena/>.Acesso em 29 de agosto 2021)

PFIZER, Bula do medicamento Alprazolam.2020

SILVA, SÁVIO A interação do álcool com medicamentos e seus efeitos no organismo. FACULDADE DE EDUCAÇÃO E MEIO AMBIENTE. Disponível em: <https://repositorio.faema.edu.br/bitstream/123456789/1255/I/SILVA\%2C\%20 S.\%20V.\%20L.\%20\%20A\%20INTERA\%C3\%87\%C3\%83O\%20DO\%20\%C3\%8ILCO OL\%20COM\%2oMEDICAMENTOS\%20E\%20SEUS\%2oEFEITOS\% 20NO\%20OR GANISMO.pdf $>$. Acesso em 24 outubro 2021 